\title{
Rare lung diseases I - Lymphangioleiomyomatosis
}

\author{
Stephen C Juvet $\mathrm{MD}^{1}$, David Hwang MD PhD², Gregory P Downey MD ${ }^{1,3}$
}

\begin{abstract}
SC Juvet, D Hwang, GP Downey. Rare lung diseases I Lymphangioleiomyomatosis. Can Respir J 2006;13(7):375-380.
\end{abstract}

The present article is the first in a series that will review selected rare lung diseases. The objective of this series is to promote a greater understanding and awareness of these unusual conditions among respirologists. Each article will begin with a case that serves as a focal point for a discussion of the pathophysiology and management of the particular condition. The first article is on lymphangioleiomyomatosis (LAM); subsequent articles will focus on pulmonary alveolar proteinosis, alpha-1-antitrypsin deficiency and primary ciliary dyskinesia.

LAM is a rare, progressive and (without intervention) often fatal interstitial lung disease that predominantly affects women of childbearing age. LAM is characterized by progressive interstitial infiltration of the lung by smooth muscle cells, resulting in diffuse cystic changes of the lung parenchyma. The molecular basis of this disorder has been delineated over the past five years and LAM is now known to be a consequence of mutations in the tuberous sclerosis genes. This knowledge, combined with advances in our understanding of the signalling pathways regulated by these genes, has given rise to potential molecular therapies that hold great promise for treating this devastating disease.

Key Words: Chylothorax; Lymphatic channels; Molecular therapy; Pneumothorax; Sirolimus; Tuberous sclerosis

\section{Maladies pulmonaires rares I - Lymphangioléiomyomatose}

\begin{abstract}
Le présent article est le premier d'une série qui passera en revue certaines maladies pulmonaires rares. L'objectif de cette série est de promouvoir une meilleure compréhension de ces maladies rares et de sensibiliser les pneumologues à leur existence. Chaque article commencera par une histoire de cas qui servira de point de départ à la présentation de la physiopathologie et du traitement de la maladie en question. Le premier article porte sur la lymphangioléiomyomatose (LAM). Les articles suivants traiteront de la protéinose alvéolaire pulmonaire, de la carence en alpha-1-antitrypsine et de la dyskinésie ciliaire primaire.

La LAM est une maladie pulmonaire interstitielle rare, évolutive et, faute d'intervention, souvent fatale, qui affecte surtout les femmes en âge de procréer. La LAM se caractérise par une infiltration interstitielle progressive des poumons par de cellules musculaires lisses, ce qui entraîne des anomalies kystiques diffuses dans le parenchyme pulmonaire. Le fondement moléculaire de cette maladie a été identifié au cours des cinq dernières années et la LAM est désormais connue comme la conséquence de mutations affectant les gènes associés à la sclérose tubéreuse de Bourneville. Cette découverte, alliée aux progrès de nos connaissances sur les voies de signalisation régis par les gènes en question, a ouvert la voie à des thérapies moléculaires potentiellement prometteuses pour le traitement de cette maladie gravissime.
\end{abstract}

\section{CASE PRESENTATION}

A 32-year-old woman presented with a four-month history of progressive fatigue and exertional dyspnea. She had no history of a cutaneous disorder, seizures, or renal or cranial tumours. She was a lifelong nonsmoker. Her mother, grandmother and maternal aunt had carcinoma of the breast. Her father had diabetes mellitus and coronary artery disease. The patient was currently enrolled in university as a graduate student.

On examination, the patient was in no acute distress. Her vital signs were normal and her respiratory rate was 16 breaths $/ \mathrm{min}$. A head and neck examination was unremarkable. There was no evidence of digital clubbing, lymphadenopathy, oral ulcers or skin lesions. Dullness to percussion and decreased breath sounds were evident over the right lower lung field. A cardiovascular examination was unremarkable, and no organomegaly, masses or ascites were detectable in the abdomen.

Chest radiography revealed a moderate-sized right pleural effusion (Figure 1). Thoracentesis yielded milky pleural fluid, which biochemical analysis revealed to be chylous. Over the next several months, the effusion recurred every three to four weeks, requiring repeated thoracentesis. The patient was subsequently admitted for pleurodesis. Computed tomography (CT) of the chest showed bilateral pulmonary interstitial thickening and diffuse cystic changes (Figure 2). Video-assisted thoracoscopy with talc pleurodesis was performed. A lung biopsy showed abnormal smooth muscle cell proliferation that was characteristic of lymphangioleiomyomatosis (LAM) (Figure 3).

\section{LAM}

LAM is a rare interstitial lung disease that predominantly affects women (1). LAM occurs in two main forms: tuberous sclerosis complex (TSC)-associated LAM (TSC-LAM) and sporadic LAM (S-LAM).

\begin{abstract}
Clinical features
Patients with TSC-LAM typically have features of tuberous sclerosis that include central nervous system (CNS) hamartomas, developmental delay and seizures. The cutaneous manifestations include hypomelanic macules (ash leaf spots), shagreen patches over the lower back or nape of the neck, subungual fibromas, skin tags and café-au-lait spots. Phakomas
\end{abstract}

\footnotetext{
${ }^{1}$ Division of Respirology, Department of Medicine; ${ }^{2}$ Department of Laboratory Medicine and Pathobiology, University of Toronto;

${ }^{3}$ Toronto General Hospital Research Institute of the University Health Network, Toronto, Ontario

Correspondence: Dr Gregory P Downey, Division of Respirology, Department of Medicine, Room 6264 Medical Sciences Building,

1 King's College Circle, University of Toronto, Toronto, Ontario M5S 1A8. Telephone 416-340-4800 ext 4591, fax 416-340-3109,

e-mail gregory.downey@uhn.on.ca
} 


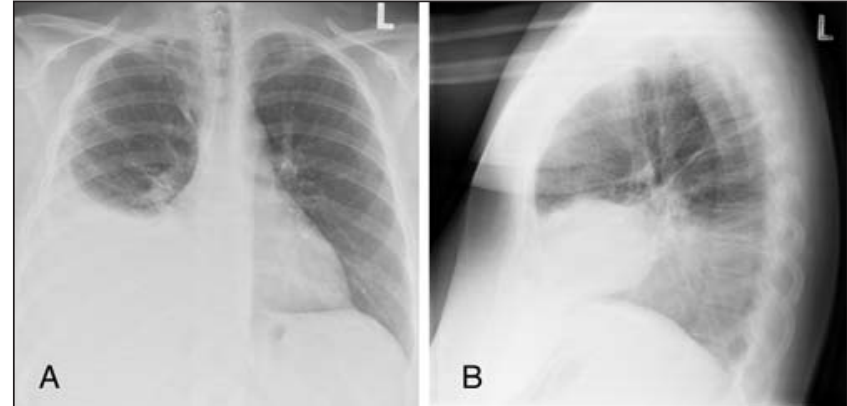

Figure 1) Posteroanterior (A) and lateral (B) chest radiographs showing a right pleural effusion. A fine reticulonodular pulmonary infiltrate is also apparent

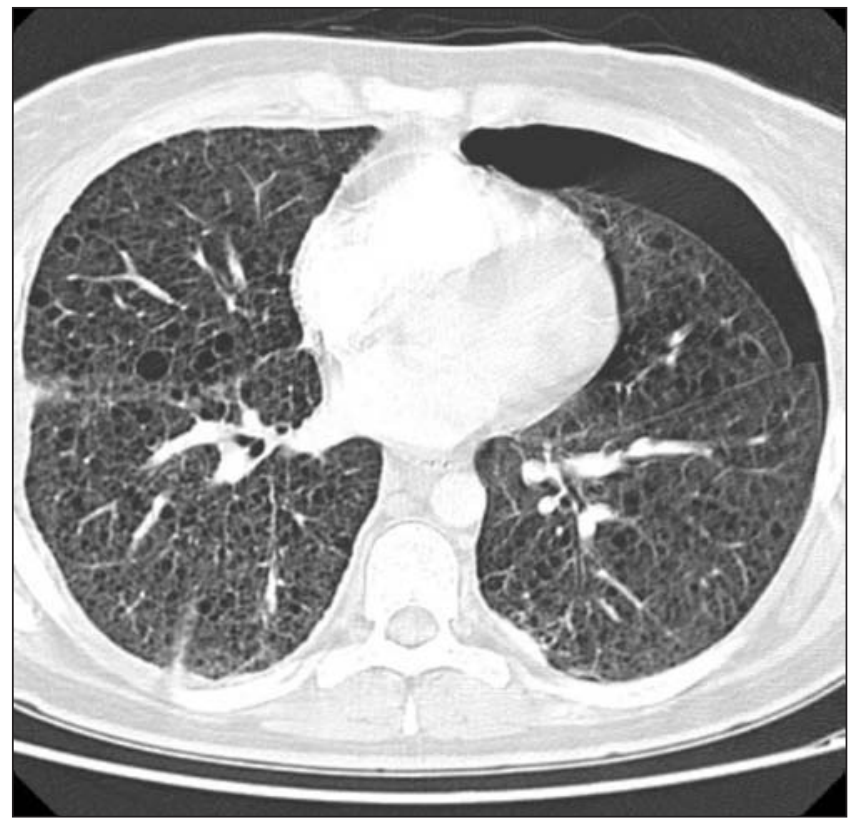

Figure 2) Computed tomography scan of the chest showing diffuse thin-walled cystic changes of the pulmonary parenchyma and left-sided pneumothorax, all findings characteristic of lymphangioleiomyomatosis. Residual chylothorax is also seen in the right hemithorax

found in the retina may be diagnostically useful but do not usually result in visual loss. TSC can be an autosomal dominant disorder but, in approximately $60 \%$ of cases, it is due to sporadic mutations in the TSC1 or TSC2 genes. Usually, TSC develops in the setting of a germline mutation in one of the two alleles for TSC1 or TSC2, and a second 'hit' in one of the patient's somatic cells triggers hamartoma formation.

\section{Molecular basis of TS and LAM}

TSC1 encodes the protein hamartin, while TSC2 encodes the protein tuberin. These proteins interact and modulate a signalling pathway that regulates cell proliferation and size in response to growth factor stimulation. Growth factor receptors at the cell membrane trigger activation of a signalling cascade involving phosphatidylinositol 3-kinase, Akt and mammalian target of rapamycin (mTOR) (Figure 4). In turn, mTOR can activate other proteins, which leads to enhanced protein synthesis and cell growth. Importantly, tuberin and hamartin form a complex that acts to inhibit mTOR. In TSC and LAM, the hamartin-tuberin complex is absent and, therefore, the mTOR

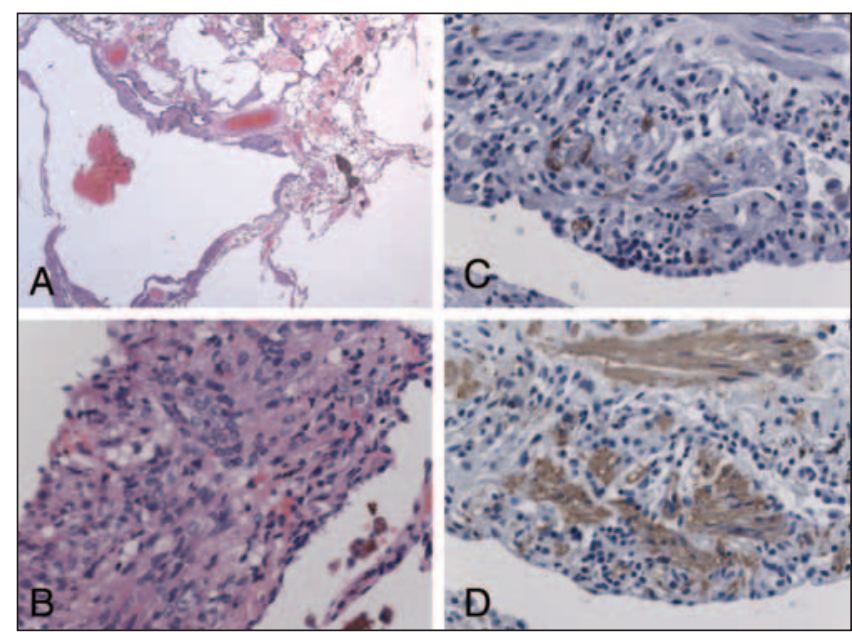

Figure 3) Histopathology of lymphangioleiomyomatosis. A Low-power (original magnification $\times 16$ ) view showing a cystic space lined by a thickened interstitium. B High-power (original magnification $\times 400$ ) view of the pulmonary interstitium showing a proliferation of smooth muscle cells. A few hemosiderin-laden macrophages can be seen in the adjacent air space. Immunohistochemical staining of specimens (original magnification $\times 400$ ) for human melanoma, black-45 (HMB-45) (C) and smooth muscle actin (D) showing the unique phenotype of the lymphangioleiomyomatosis cell

pathway is constitutively active, leading to hamartoma formation in the skin, kidney and brain, and smooth muscle proliferation in the lung.

LAM occurs in approximately one-third of patients with tuberous sclerosis but, in general, is less severe than in patients with S-LAM (2). Interestingly, LAM is only very rarely seen in men with TSC (3).

Aside from LAM, TSC is also associated with a pulmonary disorder known as multifocal micronodular pneumocyte hyperplasia (MMPH) (4). MMPH is the result of type II pneumocyte proliferation, and is characterized by micronodular changes on CT. Its functional and clinical significance remain unclear (1); however, it may coexist with TSC-LAM or S-LAM.

S-LAM occurs in women of childbearing age and is not usually associated with hamartomatous disease of the CNS or skin, but is frequently associated with renal angiomyolipomas (AMLs). S-LAM results from the loss of heterozygosity in somatic cells in the TSC2 gene and does not occur on a familial basis. S-LAM is not associated with germline mutations in either TSC1 or TSC2 and, therefore, it is not transmissible to offspring. S-LAM has never been documented in men.

\section{Clinical presentation of LAM}

There are several common clinical presentations of LAM. Typically, the patient with S-LAM is a premenopausal woman who presents with slowly progressive exertional dyspnea, chronic nonproductive cough and spontaneous pneumothorax or chylothorax. Breathlessness is the most common symptom of S-LAM and, in one study, was reported to occur in threequarters of patients (5). Moreover, just over one-half of these patients had previous spontaneous pneumothoraces, and a pleural effusion occurred in approximately 20\%. Less common presenting features include hemoptysis and chyloptysis. Due to the rarity of LAM, patients are often misdiagnosed with more common diseases such as asthma or emphysema, leading to delays of up to three to four years before diagnosis (6). 


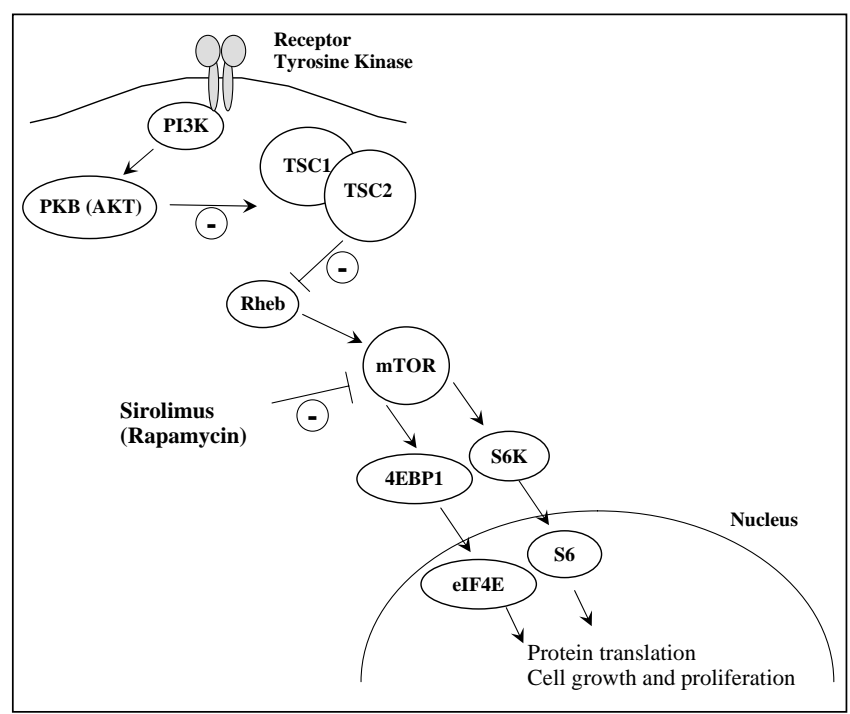

Figure 4) The mammalian target of rapamycin (mTOR) signalling cascade. mTOR is a key regulator of cell growth and protein synthesis, and its activity is influenced by the hamartin-tuberin complex, encoded by the genes tuberous sclerosis complex 1 (TSC1) and TSC2. The absence of hamartin or tuberin results in the constitutive activation of the mTOR pathway, leading to uncontrolled smooth muscle cell growth. 4EBP1 $4 E$ binding protein 1; eIF4E Eukaryotic translation initiation factor 4EBP1; PI3K Phosphatidylinositol 3-kinase; PKB Protein kinase B; Rheb Ras homolog enriched in brain; S6K S6 kinase

\section{Radiographic abnormalities}

Plain chest radiography often suggests hyperinflation, and usually reveals a reticular or reticulonodular interstitial pattern (7) (Figure 1). A pleural effusion and/or pneumothorax may also be present. Cysts and bullae may be visualized, but their extent and number are usually only apparent on high-resolution CT scans of the chest that reveal numerous thin-walled (less than $4 \mathrm{~mm}$ thickness) cysts distributed throughout the lung fields (Figure 2) $(5,7,8)$. Diffuse nodular changes consistent with MMPH may be seen in patients with TSC-LAM (4). It is important to recognize that other diffuse cystic lung diseases can be confused with LAM radiographically, including pulmonary Langerhans cell histiocytosis (Figure 5), lymphocytic interstitial pneumonia (Figure 6) and honeycombing due to advanced pulmonary fibrosis (9).

\section{Pulmonary function abnormalities}

Spirometry often reveals airflow limitation in LAM, while lung volume measurements may show a restrictive pattern with gas trapping, leading to a mixed obstructive and restrictive pattern $(6,8)$. Consistent with the relative predominance of airflow limitation in patients with LAM, hyperinflation is also observed. A bronchodilator response is observed in approximately one-quarter of patients with LAM, and this has important clinical implications $(5,9)$. Impaired diffusion is one of the most common findings in LAM, reflecting the diffuse pulmonary interstitial involvement by the disease process (Figure 3). Finally, exercise testing often reveals significant ventilatory limitation and profound arterial oxygen desaturation (10).

\section{Pathology of LAM}

Gross specimens of lung tissue from LAM patients exhibit numerous cystic spaces, creating a honeycomb appearance. The spaces are usually filled with air but may contain serosanguineous fluid or chyle (1). The pathophysiology of cyst formation is

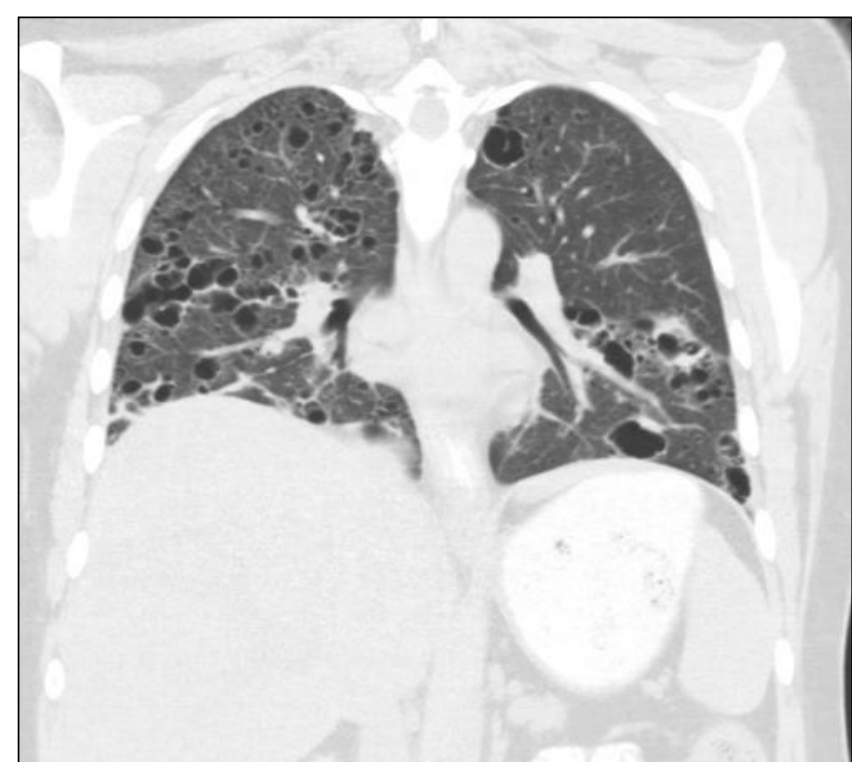

Figure 5) High-resolution computed tomography scan of the chest in a patient with pulmonary Langerhans cell histiocytosis showing the cystic parenchymal changes characteristic of this disease, which can be confused with those seen in lymphangioleiomyomatosis

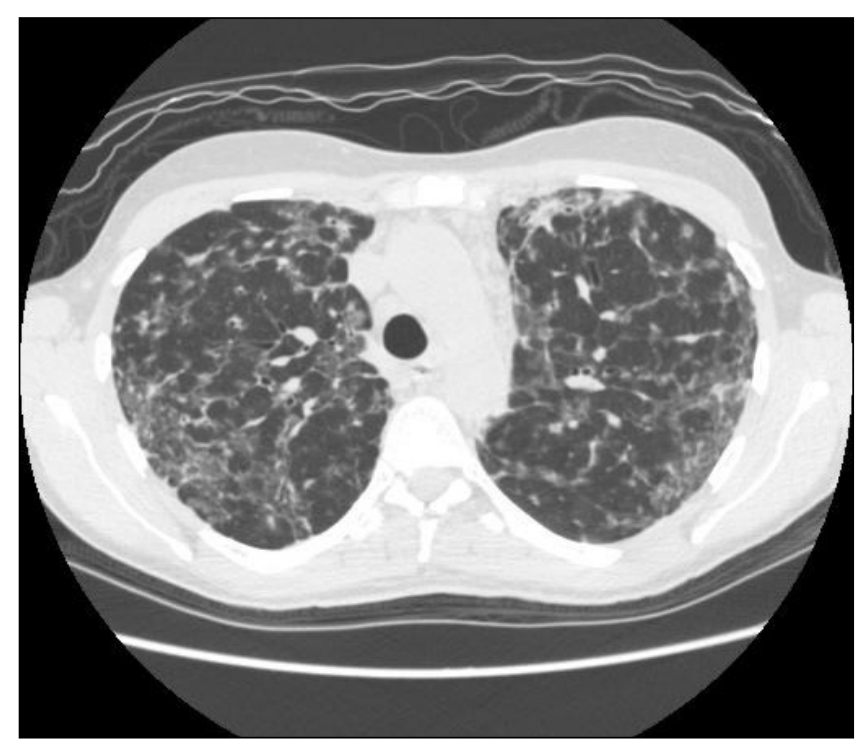

Figure 6) High-resolution computed tomography scan of the chest in a patient with lymphocytic interstitial pneumonia, illustrating the diffuse cyst formation frequently observed in this disorder

uncertain but likely reflects, in part, obstruction of distal airways by proliferating smooth muscle, creating a check-valve effect.

Histologically, the pulmonary interstitium is filled with spindle-shaped smooth muscle-like cells. The cells are found in the cyst walls and are located in close proximity to the pulmonary lymphatic vessels and vasculature (1). The intimate relationship of LAM lesions to the lymphatic vessels is believed to be responsible for chylothorax formation. Phenotypically, LAM cells resemble both smooth muscle cells (on the basis of alpha-actin staining) (11) and fibroblasts (on the basis of fibroblast antigen expression). Human melanoma, black-45 (HMB-45) antibody, which reacts with glycoprotein 100 of melanoma cells, may stain LAM cells positively (12), although this is more variable than in melanoma cells. 
Renal hamartomatous lesions, known as angiomyolipomas (AMLs), containing fat, smooth muscle and blood vessels are found in $50 \%$ of patients with S-LAM $(8,13)$ and up to $88 \%$ with TSC-LAM (5); AMLs tend to be single lesions in the former condition and multiple or bilateral in the latter condition. On abdominal CT scans, AMLs appear as mixed density lesions containing fat and soft tissue. Although they are nonmalignant lesions, AMLs have the potential to create significant problems, including renal failure by compression of normal renal tissue. In fact, there is a spectrum of illnesses relating to AMLs, ranging from an asymptomatic state (discovered on screening abdominal imaging) to severe hemorrhage and shock. Intermittent flank pain is a common symptom in patients who have renal AMLs.

Less commonly, extrarenal AMLs may be seen in patients with LAM. There may also be evidence of retroperitoneal lymphadenopathy, lymphangiomas and chylous ascites. The latter case, which is often accompanied by elevations in the serum level of cancer antigen 125, may lead to a false suspicion of ovarian carcinoma.

Benign tumours of the CNS in patients with LAM may suggest a diagnosis of TSC. A variety of CNS lesions have been described, including meningiomas, cortical tubers, subependymal nodules and astrocytomas. Such lesions may be asymptomatic, or they may be associated with focal neurological deficits, seizures and developmental delay (14). A history of an unexplained seizure disorder in a patient presenting with S-LAM should suggest the diagnosis of TSC. Similarly, consideration should be given to performing a screening CT scan of the head or magnetic resonance imaging to exclude subclinical CNS lesions related to TSC in patients presenting with S-LAM.

\section{Prognosis}

Past research examining the prognosis of patients with LAM reported a five-year survival rate of approximately 50\% (15). However, more recent data suggest a substantially better prognosis, with five-year survival rates as high as $90 \%$ (16). Because there has been little change in the therapy of LAM over this time, these differences are likely attributable to the nonrepresentative nature of the small numbers of patients included in earlier series (1). Patients with LAM who undergo lung transplantation have generally had their disease for 10 to 11 years (17). Interestingly, the five-year survival rate for patients who have undergone lung transplantation in the Toronto Lung Transplant Program for LAM is approximately $60 \%$, which is better than the general survival rate for all lung transplant recipients of approximately 50\% (unpublished data).

\section{Clinical management of LAM}

Patients presenting with LAM should be counselled regarding smoking cessation because exposure to tobacco smoke may compound the airway abnormalities in LAM and increase the risk of pneumothorax. A trial period using bronchodilators is appropriate when reversible airflow limitation is present on pulmonary function testing. Additionally, oxygen should be prescribed to patients who meet the standard criteria for domiciliary oxygen therapy. Patients with LAM are often excellent candidates for pulmonary rehabilitation, given their young age and lack of comorbid illnesses. However, it is important to note that the benefits of pulmonary rehabilitation have not been specifically documented in this population.
Patients who have significant chylothoraces should receive dietary advice regarding a low-fat diet, and should consider dietary supplementation with medium-chain triglycerides. These measures help to minimize the generation of chyle in the intestinal lymphatic vessels, decreasing the quantity of chyle delivered to the thoracic duct, which may delay the need for surgical intervention.

Many experts agree that, in the appropriate clinical setting, a characteristic high-resolution CT scan of the lungs is sufficient for the diagnosis of LAM and a confirmatory biopsy may not be necessary. Examples of such situations include patients who present with known TSC, recurrent pneumothorax, chylothorax or renal AML. Lung biopsy, typically via a video-assisted thoracoscopic approach, should be considered when there is doubt about the diagnosis or when there are one or more alternative diagnostic possibilities with different therapies.

\section{Sex hormonal implications in LAM}

The possibility that estrogens may play a role in the pathogenesis of LAM is suggested by observations that the disease generally presents in premenopausal women, and is frequently exacerbated by oral contraceptive use $(5,18)$, pregnancy $(19,20)$ and during the onset of menses $(5)$. Moreover, in the few reported cases of LAM in postmenopausal women, the disease course tends to be more indolent (21). These observations, and the finding that LAM tissue (22) and AMLs (23) express estrogen and progesterone receptors, have led to a number of hormone-based treatment recommendations. Patients should be advised not to use estrogen-containing medications such as oral contraceptives. In addition, women should be advised that pregnancy may exacerbate LAM and that following pregnancy, lung function may not return to baseline (18).

The only meta-analysis of LAM therapies concluded that progesterone and oophorectomy are the most effective therapies (24). However, this conclusion was based on an analysis of pooled results from published single cases or small series, totalling 30 patients. Furthermore, the authors judged only 12 of these cases to have been studied objectively enough to warrant inclusion in their analysis, which also did not consider the adverse effects of therapy.

Commonly used progesterone regimens are a $400 \mathrm{mg}$ monthly intramuscular injection or daily oral medroxyprogesterone at a dose of $10 \mathrm{mg}$ to $20 \mathrm{mg}$. Just over one-half of the patients in a national LAM registry were being treated with progesterone at the time of enrollment (5). Importantly, recent data indicate that progesterone lacks efficacy in LAM and may, in fact, accelerate the decline in the diffusing capacity of the lung for carbon monoxide (25). Tamoxifen, a partial estrogen receptor antagonist, has also been used, but appears to worsen the disease in some women (5). Moreover, hormonal treatment is often associated with significant adverse effects such as mood swings and fluid retention. In the past, bilateral oophorectomy and ovarian irradiation were used in the treatment of LAM, but are no longer recommended because the overall benefit of these treatments is unknown in the face of the clearly increased associated risk of cardiovascular disease and osteoporosis. Given the limited evidence on the efficacy of hormonal therapy, many experts now recommend against its routine use.

\section{Management of pneumothorax in LAM}

Current recommendations stipulate that the first pneumothorax in a patient with LAM should be treated with pleurodesis, 
because once a pneumothorax has occurred, recurrent pneumothoraces are likely $(1,5)$. A major concern regarding pleurodesis, especially with talc, is that the pleural reaction induced by this procedure can make a subsequent lung transplant technically difficult. Severe hemorrhage can occur intraoperatively as a result of numerous pleural adhesions, although this can also result from recurrent pneumothoraces or the disease process itself (17). Importantly, many patients who have undergone pleurodesis have subsequently had successful lung transplantation and, thus, pleurodesis is no longer considered to be an absolute contraindication to transplant in many centres.

\section{Lung transplantation in LAM}

Lung transplantation should be considered when severe hypoxemia or marked physiological derangement develops in association with a diminished quality of life. In general, referral to a transplant centre should be considered when the forced expiratory volume in $1 \mathrm{~s}$ approaches $30 \%$ of predicted, although earlier referral may be indicated in patients with rapidly declining lung function or refractory recurrent pneumothoraces. Typically, patients with LAM are excellent candidates for lung transplantation, given their relatively young age and lack of comorbid illnesses. The worldwide experience in lung transplantation for LAM now exceeds 130 patients (26). The majority of these have been extremely successful. In addition to the potential complications associated with lung transplantation, there is a low but definite risk of LAM recurrence in the allograft $(27,28)$. As such, counselling about this possibility is important for patients with LAM who are being considered for lung transplantation.

\section{Experimental therapies for LAM}

An understanding of the molecular pathogenesis of LAM has opened a number of avenues for future therapies of this disorder. Inhibition of the mTOR pathway with rapamycin (sirolimus) is

\section{REFERENCES}

1. Glassberg MK. Lymphangioleiomyomatosis. Clin Chest Med 2004;25:573-82,vii.

2. Moss J, Avila NA, Barnes PM, et al. Prevalence and clinical characteristics of lymphangioleiomyomatosis (LAM) in patients with tuberous sclerosis complex. Am J Respir Crit Care Med 2001;164:669-71.

3. Aubry MC, Myers JL, Ryu JH, et al. Pulmonary lymphangioleiomyomatosis in a man. Am J Respir Crit Care Med 2000;162:749-52.

4. Franz DN, Brody A, Meyer C, et al. Mutational and radiographic analysis of pulmonary disease consistent with lymphangioleiomyomatosis and micronodular pneumocyte hyperplasia in women with tuberous sclerosis. Am J Respir Crit Care Med 2001;164:661-8.

5. Ryu JH, Moss J, Beck GJ, et al; NHLBI LAM Registry Group. The NHLBI lymphangioleiomyomatosis registry: Characteristics of 230 patients at enrollment. Am J Respir Crit Care Med 2006; 173:105-11.

6. Oberstein EM, Fleming LE, Gomez-Marin O, Glassberg MK. Pulmonary lymphangioleiomyomatosis (LAM): Examining oral contraceptive pills and the onset of disease. J Womens Health (Larchmt) 2003;12:81-5.

7. Kirchner J, Stein A, Viel K, et al. Pulmonary lymphangioleiomyomatosis: High-resolution CT findings. Eur Radiol 1999;9:49-54.

8. Chu SC, Horiba K, Usuki J, et al. Comprehensive evaluation of 35 patients with lymphangioleiomyomatosis. Chest 1999;115:1041-52.

9. Ryu JH, Swensen SJ. Cystic and cavitary lung diseases: Focal and diffuse. Mayo Clin Proc 2003;78:744-52.

10. Crausman RS, Jennings CA, Mortenson RL, Ackerson LM, Irvin CG, King TE Jr. Lymphangioleiomyomatosis: The pathophysiology of diminished exercise capacity. Am J Respir Crit Care Med 1996;153:1368-76. a logical strategy, because this agent is already in use as an immunosuppressive drug in the setting of solid organ transplantation (29). Enthusiasm for the use of sirolimus in LAM is tempered by its pulmonary toxicity, which can be severe (30). Moreover, it is unclear whether the presence of pulmonary LAM may predispose patients to the development of this toxicity. The sirolimus Multicentre International Lymphangioleiomyomatosis Efficacy and Safety (MILES) trial, based at the University of Cincinnati (Cincinnati, Ohio), has recently been approved by the National Institutes of Health, and is scheduled to begin shortly, with the aim to address this issue.

There is still much to be learned about LAM. The finding that the progression and recurrence of LAM occurs via a metastatic mechanism (28) requires further clarification. Moreover, the fact that LAM occurs almost exclusively in women mandates further study of the signalling pathways modulated by estrogen and progesterone, as well as how these pathways interact with hamartin and tuberin. Ultimately, these investigations will guide prospective randomized trials of targeted therapies. The rarity of LAM makes international, multicentre collaboration at all levels of investigation essential (31).

\section{CONCLUSIONS}

LAM is a prototypical example of how the careful study of a rare disease can unlock the basic molecular underpinnings of illness. Over the past decade, the pathogenesis of LAM has become more clearly understood, offering hope to patients suffering from this devastating illness.

ACKNOWLEDGEMENTS: This study was supported by an operating grant from the Canadian Institutes of Health Research to Dr Gregory Downey. Dr Downey is a Tier 1 Canada Research Chair in Respiration Sciences. The authors thank Dr Frank McCormack for critical review of the manuscript.

11. Chan JK, Tsang WY, Pau MY, Tang MC, Pang SW, Fletcher CD. Lymphangiomyomatosis and angiomyolipoma: Closely related entities characterized by hamartomatous proliferation of HMB-45-positive smooth muscle. Histopathology 1993;22:445-55.

12. Ferrans VJ, Yu ZX, Nelson WK, et al. Lymphangioleiomyomatosis (LAM): A review of clinical and morphological features. J Nippon Med Sch 2000;67:311-29.

13. Bernstein SM, Newell JD Jr, Adamczyk D, Mortenson RL, King TE Jr, Lynch DA. How common are renal angiomyolipomas in patients with pulmonary lymphangiomyomatosis? Am J Respir Crit Care Med 1995;152:2138-43.

14. Sparagana SP, Roach ES. Tuberous sclerosis complex. Curr Opin Neurol 2000;13:115-9.

15. Kitaichi M, Nishimura K, Itoh H, Izumi T. Pulmonary lymphangioleiomyomatosis: A report of 46 patients including a clinicopathologic study of prognostic factors. Am J Respir Crit Care Med 1995;151:527-33.

16. Urban T, Lazor R, Lacronique J, et al. Pulmonary lymphangioleiomyomatosis. A study of 69 patients. Groupe d'Etudes et de Recherche sur les Maladies "Orphelines" Pulmonaires (GERM“O”P). Medicine (Baltimore) 1999;78:321-37.

17. Boehler A, Speich R, Russi EW, Weder W. Lung transplantation for lymphangioleiomyomatosis. N Engl J Med 1996;335:1275-80.

18. Yano S. Exacerbation of pulmonary lymphangioleiomyomatosis by exogenous oestrogen used for infertility treatment. Thorax 2002;57:1085-6.

19. Yockey CC, Riepe RE, Ryan K. Pulmonary lymphangioleiomyomatosis complicated by pregnancy. Kans Med 1986;87:277-8,293.

20. Weinans MJ, van Loon AJ. A diagnosis of lymphangioleiomyomatosis in a pregnant woman presenting with a retroperitoneal mass. Br J Obstet Gynaecol 1999;106:747-8. 
21. Baldi S, Papotti M, Valente ML, Rapellino M, Scappaticci E, Corrin B. Pulmonary lymphangioleiomyomatosis in postmenopausal women: Report of two cases and review of the literature. Eur Respir J 1994;7:1013-6.

22. Matsui K, Takeda K, Yu ZX, et al. Downregulation of estrogen and progesterone receptors in the abnormal smooth muscle cells in pulmonary lymphangioleiomyomatosis following therapy. An immunohistochemical study. Am J Respir Crit Care Med 2000;161:1002-9.

23. Logginidou H, Ao X, Russo I, Henske EP. Frequent estrogen and progesterone receptor immunoreactivity in renal angiomyolipomas from women with pulmonary lymphangioleiomyomatosis. Chest 2000;117:25-30.

24. Eliasson AH, Phillips YY, Tenholder MF. Treatment of lymphangioleiomyomatosis. A meta-analysis. Chest 1989;96:1352-5.

25. Taveira-DaSilva AM, Stylianou MP, Hedin CJ, Hathaway O, Moss J. Decline in lung function in patients with lymphangioleiomyomatosis treated with or without progesterone. Chest 2004;126:1867-74.
26. Trulock EP, Edwards LB, Taylor DO, Boucek MM, Keck BM, Hertz MI. Registry of the International Society for Heart and Lung Transplantation: Twenty-second official adult lung and heart-lung transplant report - 2005. J Heart Lung Transplant 2005;24:956-67.

27. O'Brien JD, Lium JH, Parosa JF, Deyoung BR, Wick MR, Trulock EP. Lymphangiomyomatosis recurrence in the allograft after single-lung transplantation. Am J Respir Crit Care Med 1995;151:2033-6.

28. Karbowniczek M, Astrinidis A, Balsara BR, et al. Recurrent lymphangiomyomatosis after transplantation: Genetic analyses reveal a metastatic mechanism. Am J Respir Crit Care Med 2003;167:976-82.

29. Yakupoglu YK, Kahan BD. Sirolimus: A current perspective. Exp Clin Transplant 2003;1:8-18.

30. Garrean S, Massad MG, Tshibaka M, Hanhan Z, Caines AE, Benedetti E. Sirolimus-associated interstitial pneumonitis in solid organ transplant recipients. Clin Transplant 2005;19:698-703.

31. NHLBI Workshop Summary. Report of workshop on lymphangioleiomyomatosis. National Heart, Lung, and Blood Institute. Am J Respir Crit Care Med 1999;159:679-83. 


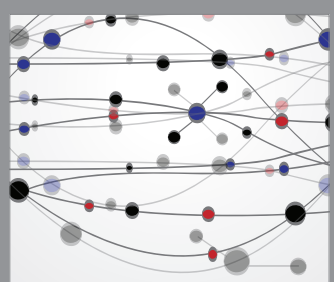

The Scientific World Journal
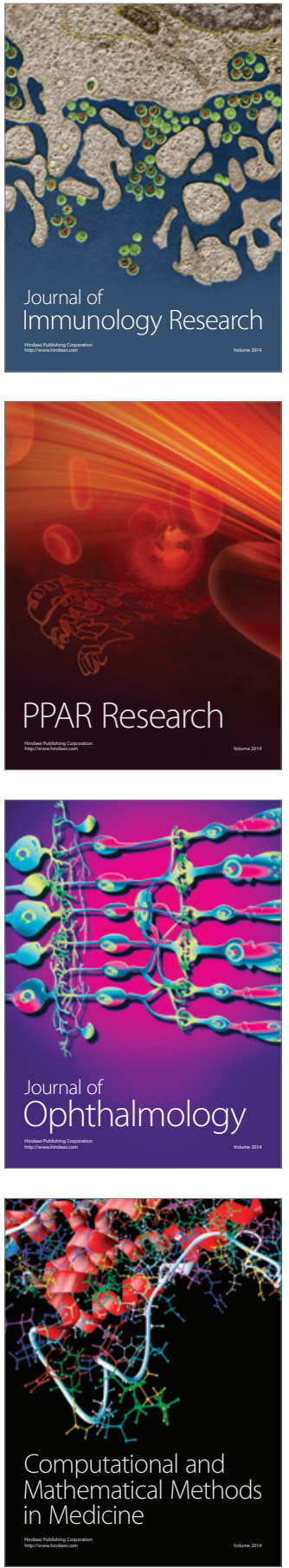

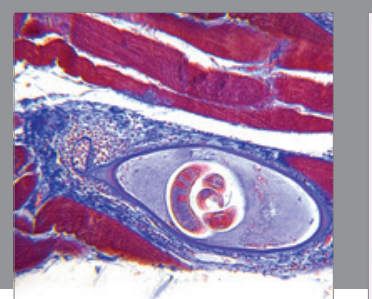

Gastroenterology Research and Practice

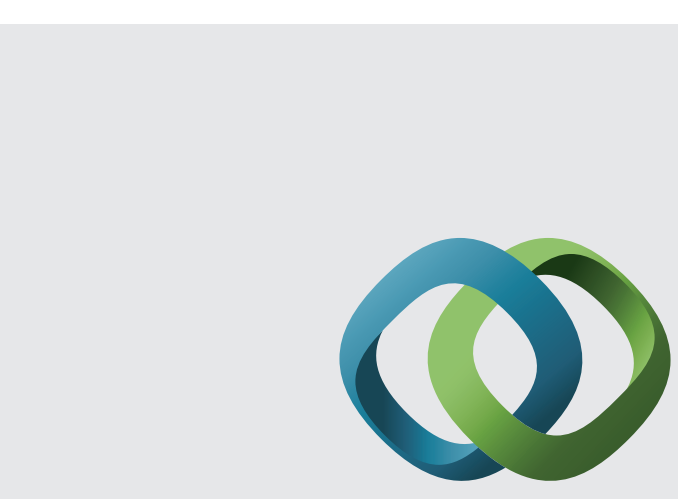

\section{Hindawi}

Submit your manuscripts at

http://www.hindawi.com
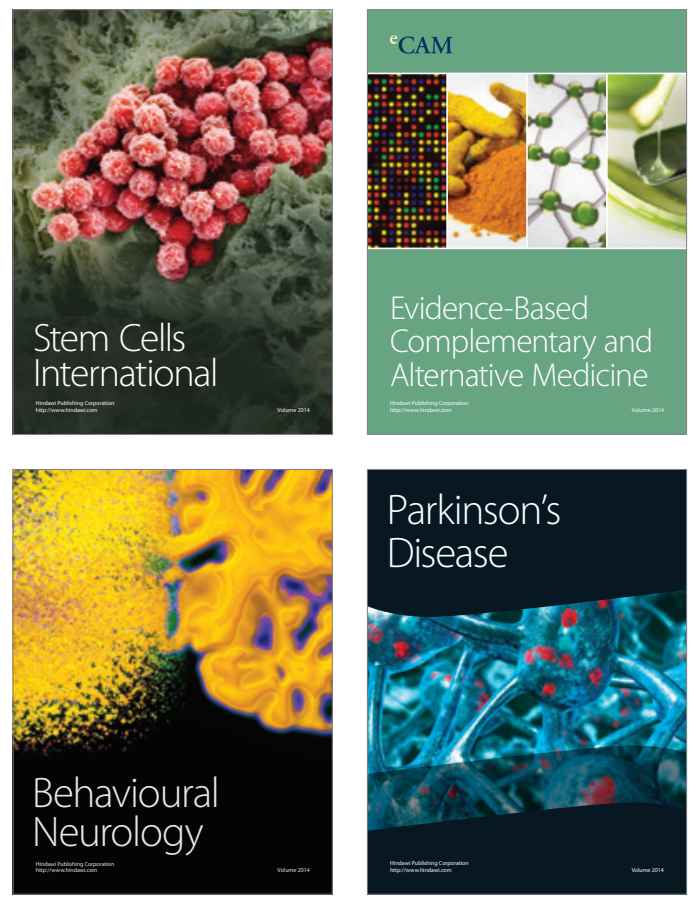
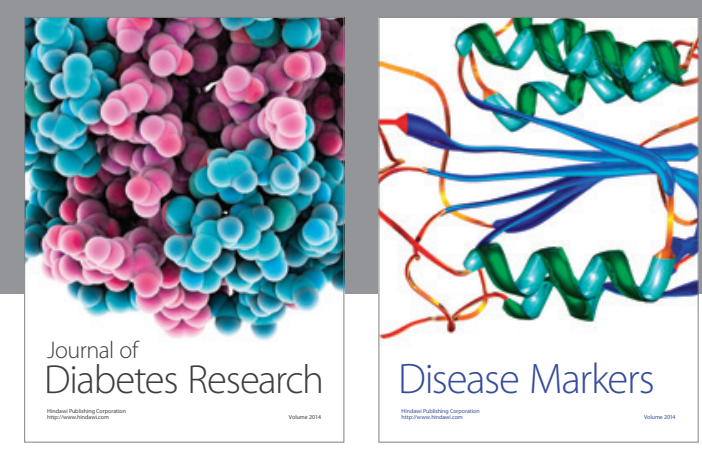

Disease Markers
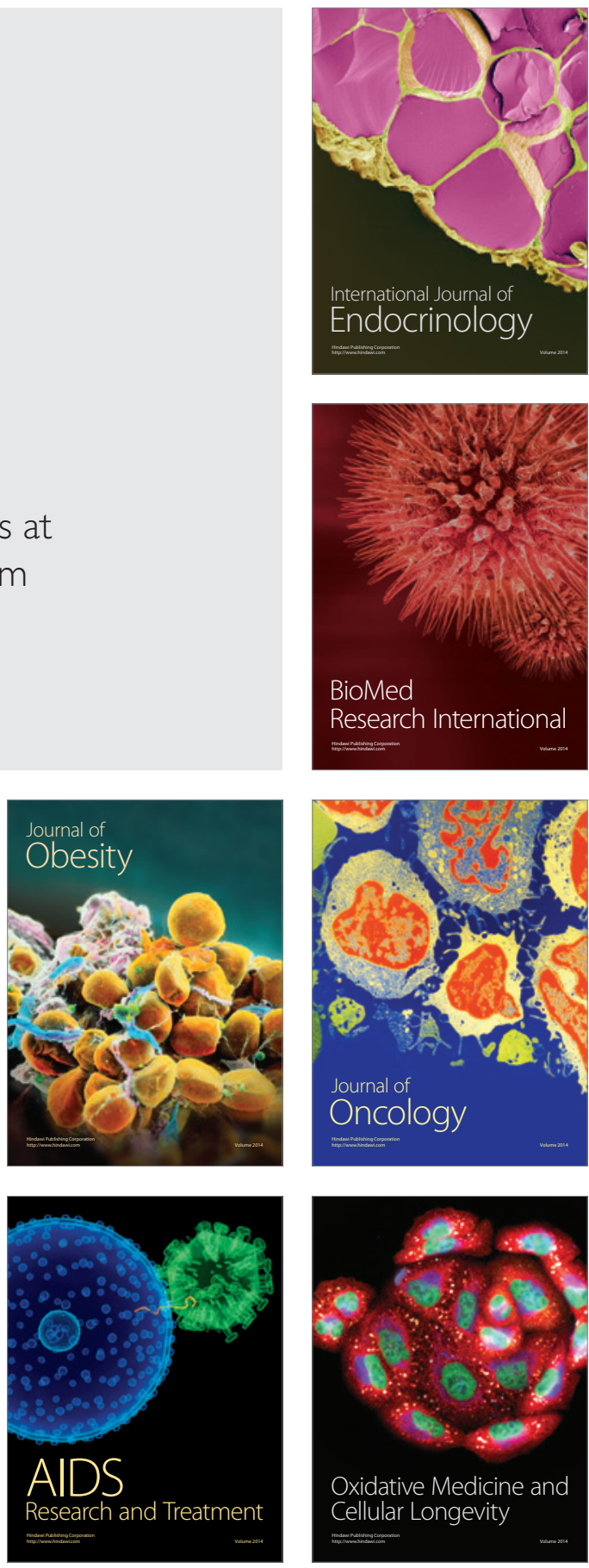